\title{
CFD Analysis of Exhaust Manifold of SI Engine and Comparison of Back Pressure using Alternative Fuels
}

\author{
Kanupriya Bajpai ${ }^{1}$, Akash Chandrakar ${ }^{2}$, Akshay Agrawal ${ }^{3}$, Shiena Shekhar ${ }^{4}$ \\ ${ }_{1,2,3,4}$ (Mechanical Engineering Department, BIT Durg, India)
}

\begin{abstract}
Exhaust manifold is one of the most critical components of an IC Engine. The functioning of exhaust manifold is complex and is dependent on many parameters viz. back pressure, exhaust velocity, scavenging etc. In the present work, the performance of a four-stroke four cylinder gasoline engine exhaust manifold have been analysed using three different fuels - gasoline, alcohol, and LPG for the estimation of flow characteristics, thermal characteristics, and minimum back pressure. The manifold modelling is done in Creo2.0 followed by meshing and analysis in ANSYS. The LPG fuel gives minimum back pressure, temperature and velocity being approximately in the same range for all three fuels viz. gasoline, alcohol and LPG. Thus, LPG can be considered as a suitable alternative for gasoline in terms of minimum back flow in manifold.
\end{abstract}

Keywords: Back pressure, CFD, exhaust manifold, FEM, SI engine

\section{Introduction}

Exhaust manifold is a part of IC engines, its role is to collect and carry the exhaust gases away from the cylinder head and send it to the exhaust system, with a minimum of back pressure. The exhaust manifold plays an important role in the performance of an engine system. Particularly, the efficiencies of emission and fuel consumption are closely related to the performance of exhaust manifold. Exhaust Manifolds are affected by thermal stresses and deformations due the temperature distribution, heat accumulation or dissipation and other related thermal characteristics.

The exhaust manifold is able to influence the gas exchange process in several aspects, like the piston work during the exhaust stroke, the short-circuit of fresh charge from the intake into the exhaust and even the filling of the cylinder. In this sense, the most influential boundary condition imposed by the manifold is the pressure at the valve and especially the instantaneous pressure evolution. The mean backpressure is determined mainly by the singular elements, such as the turbine, the catalytic converter and the silencer.

Special interest must be given to the back pressure parameter. Back pressure is an undesired effect because as the back pressure increases so does the amount of residuals left in the head. The increase in weight of residuals will decrease the volume of the fresh charge, in turn increasing the temperature at the beginning of compression as well. Several experiments show how the increase in back pressure influences the thermal efficiency for different induction manifold pressures.

Proper analysis of the flue gases of various fuels in exhaust manifold is a difficult exercise however use of finite element method and computational fluid dynamics has shown promise.

\section{Improvement In Exhaust Manifold Design}

The design of exhaust manifolds has been developed for many years. As engines have been improved so have exhaust manifolds. Early exhaust manifolds were much less efficient than today's exhaust manifolds. Designs that did not contribute to a smooth flow were very typical in early times. The back pressure built up was much greater, this increased the work done by the particular piston at the exhaust stroke. Large amounts of residual gases remain in the compression chamber and, as a consequence, the temperature increases. Sometimes when working hard the manifold glows red-hot, forcing the use of asbestos, a highly heat-resistant fibrous silicate mineral, to protect paintwork. Nowadays, exhaust manifold designs have been transformed completely. In order to improve earlier configurations, designers and researchers have come up with different designs with respect to various parameters that affect the exhaust manifold. Lot of work on effect of various parameters on the analysis, design, and performance of exhaust manifold has been reported.

Traditional manifold optimization has been based on tests on exhaust manifold. This trial \& error method can be effective but is very expensive and time consuming. Beside this method cannot provide any information about the actual flow structure inside the manifold. This vital information can be obtained using 3-D CFD analysis.

Umesh et al.[1-3] investigated the best possible designs for exhaust manifold from emission point of view. Jain and Agrawal [4] investigated the associated thermal stresses and deformations under simulated operational conditions close to the real situation on different materials, to ensure the appropriateness of material for the defined design from the view point of serviceability of the exhaust manifold. 
Work have also been done on estimation of flow characteristic in inlet and exhaust manifolds of internal combustion engines using a four-stroke variable compression ratio single cylinder gasoline engine by Kutaiba et al.[5]. Rathnaraj et al. [6] carried out thermo mechanical fatigue analysis of stainless steel exhaust manifolds. Swathi et al.[7] worked on the predictions obtainable using the conformal and indirect interfaces for Conjugate Heat Transfer (CHT) analysis in an exhaust manifold. Heat transfer phenomena were also investigated analytically using different Nusselt number by Durat $e t$ al.[8]. Pressure transducer location and the distortions of measured pressure courses by transducer position were investigated by Miklánek [9]. Zidat and Parmentier [10] have worked on Exhaust Manifold Design to Minimize Catalyst Light-off Time.

The complex geometry of the exhaust line and the special flow conditions complicate the problem of accurately estimating several important heat transfer parameters. Kandylas and Stamatelos [11] have investigated the engine exhaust system design based on heat transfer computation and have suggested the optimization of various parameters such as exhaust manifold material, thickness and insulation, exhaust manifold and downpipe design (geometry), position of catalytic converter in gasoline engines. Londhe and Yadav [12] studied the effect of thermal shock on the exhaust manifold. Taner Gocmez et al.[13] provided a procedure for an integral solution, which provides for the development of optimized exhaust manifolds that are failure-free.

In another study on the impact of temperature effect on exhaust manifold, thermal modal analysis, by Zou et al. [14], the temperature field was mapped from the CFD software and then heat conduction process was analysed in FEM software with the temperature field boundary conditions. Bisen et al.[15] have presented a powerful method to evaluate exhaust system performance through their work on experimental investigation and CFD analysis of a single cylinder four stroke C.I. engine exhaust system. Deger et al. [16] did CFD-FE-Analysis for the Exhaust Manifold of a Diesel Engine aiming to determine specific temperature and pressure distributions.

\section{Problem Identification}

Alternative fuels, known as non-conventional or advanced fuels, are any materials or substances that can be used as fuels, other than conventional fuels. Because of a combination of factors, such as environmental concerns, high oil prices and the potential for peak oil, development of cleaner alternative fuels and advanced power systems for vehicles has become a high priority for many governments and vehicle manufacturers around the world. However, the suitability of such alternate fuels for internal combustion engines is to be established in terms of combustion efficiency, engine power, and exhaust gases.

Exhaust system is designed to evacuate gases from the combustion chamber quickly and efficiently. Exhaust gases are not produced in a smooth stream; exhaust gases originate in pulses. Engine exhaust back pressure is defined as the exhaust gas pressure that is produced by the engine to overcome the hydraulic resistance of the exhaust system in order to discharge the gases into the atmosphere. Back pressure is one of the major factors that affect the engine exhaust gas emission.

Some of the effects of increased back pressure in an exhaust manifold are:

1. The engine has to compress the exhaust gases to a higher pressure which involves additional mechanical work and/or less energy extracted by the exhaust turbine

2. Excessive exhaust pressures can increase the likelihood of failure of turbocharger seals, resulting in oil leakage into the exhaust system.

Thus, it is important to determine minimum back pressure for proper exhaust emission for different fuels. In this work, we have considered two fuels as an alternative to gasoline, namely LPG (Liquefied petroleum gas or liquid petroleum gas (LPG or LP gas), also referred to as 'Autogas' in case of automobile fuel) and alcohol (ethanol).

\section{Process Methodology}

The reciprocating engine causes the air-flow in the exhaust manifold to oscillate with a frequency that is a multiple of the engine speed, as a result of the oscillating air-flow the pressure in the exhaust manifold will also oscillate. The exhaust manifold pressure is a crucial variable for an IC engine, affecting the torque production and the emissions through variations in the EGR mass flow and in the residual mass fraction in the cylinder. Also it is a complex system subjected to thermo mechanical loads. The analysis of such a system is critical due to the complexity of meeting the structural and flow requirements. The use of Computational Fluid Dynamics (CFD) and Finite element analysis (FEA) are inevitable tools to achieve this.

A four stroke four cylinder spark ignition engine (Swept volume 1197cc, compression ratio 10:1) exhaust manifold was taken. The analysis was performed on the exhaust manifold with alternative fuels (Table 1) in comparison with gasoline to determine flow and thermal characteristics. The results obtained are compared to determine the minimum back pressure. 
The model development was carried out on Creo2.0. ANSYS for further analysis. The four cylinder SI engine exhaust manifold was created in three different parts. These parts were then assembled to give the final model of the exhaust manifold (Fig.1). The exhaust manifold model was meshed using tetrahedral elements of T-grid scheme type with zero relevance (Fig.2). Table 2 shows inlet and outlet boundary conditions.

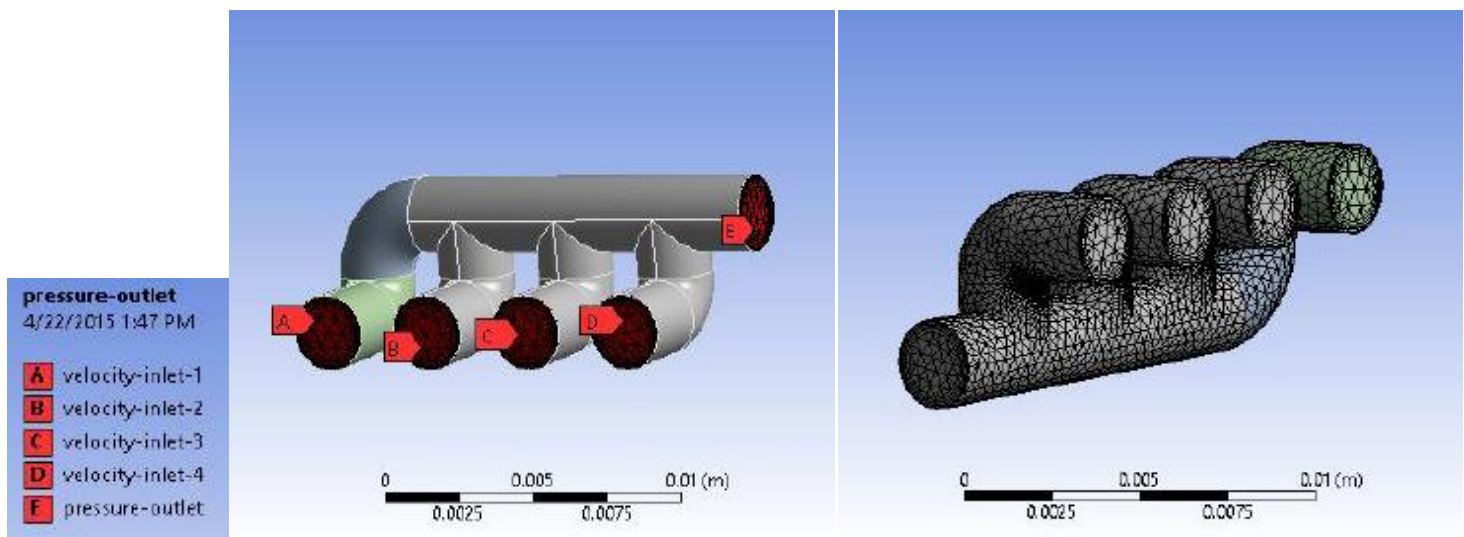

Figure 1: Solid view of exhaust manifold

Figure 2. Meshed model of the assembly

ANSYS FLUENT was used for modelling fluid flow and heat transfer. For the analysis, following assumptions were made:

1. All the walls are stationary walls with no slip as shear condition.

2. The outer surface of the wall is kept at a temperature of $300 \mathrm{~K}$ with no heat generation rate.

3. The material of the wall was taken as Aluminum.

4. There are four inlets to the system. All the four outlet valves are assumed to open at the same time and exhaust gas enter the exhaust manifold's inlets at a constant velocity.

5. The turbulence was assumed to be $10 \%$ of the Kinetic energy throughout the analysis.

6 . The compression ratio of the engine was assumed to be constant throughout the analysis.

7. Gravity was not taken into considerations.

Table 1: Material Fluid Properties used in analysis

\begin{tabular}{|l|l|l|l|}
\hline Material & Gasoline & Alcohol & LPG \\
\hline Density $\left(\mathrm{Kg} / \mathrm{m}^{3}\right)$ & 1.0685 & 1.255 & 1.2631 \\
\hline Viscosity $(\mathrm{Pa}-\mathrm{s})$ & $3.0927 \times 10^{-5}$ & $2.57 \times 10^{-5}$ & $2.57 \times 10^{-5}$ \\
\hline Specific Heat $(\mathrm{J} / \mathrm{Kg}-\mathrm{K})$ & 1056.6434 & 1150.6 & 1138.40 \\
\hline Thermal Conductivity $(\mathrm{W} / \mathrm{m}-\mathrm{K})$ & 0.0250 & 0.025 & 0.025 \\
\hline
\end{tabular}

Source: Umesh K. et al (2013)

Table 2: Inlet and Outlet Boundary Conditions

\begin{tabular}{|l|l|l|l|l|l|}
\hline Zone & $\begin{array}{l}\text { X-velocity } \\
(\mathbf{m} / \mathbf{s})\end{array}$ & $\begin{array}{l}\text { Y-velocity } \\
(\mathbf{m} / \mathbf{s})\end{array}$ & $\begin{array}{l}\text { Z-velocity } \\
(\mathbf{m} / \mathbf{s})\end{array}$ & $\begin{array}{l}\text { Turbulent } \\
\text { Intensity (\%) }\end{array}$ & $\begin{array}{l}\text { Mean Hydraulic } \\
\text { diameter }(\mathbf{m})\end{array}$ \\
\hline Velocity Inlet 1 & 0 & 0 & -17.03 & 10 & 0.00877 \\
\hline Velocity Inlet 2 & 0 & 0 & -17.03 & 10 & 0.00877 \\
\hline Velocity Inlet 3 & 0 & 0 & -17.03 & 10 & 0.00877 \\
\hline Velocity Inlet 4 & 0 & 0 & -17.03 & 10 & 0.00877 \\
\hline Pressure outlet & & 10 & 0.01302 & \\
\hline
\end{tabular}

\section{Results And Discussions}

The results obtained by CFD simulations are displayed with the help of pressure, velocity and temperature contours.

Velocity Contours (fig.3-8):

From the velocity profiles of the exhaust manifold, it can be observed that at all the inlets the velocities are same. The velocities of the gases reduce with forward movement in the $\mathrm{z}$ direction. At the four inlets as per the boundary conditions the velocity is $17.03 \mathrm{~m} / \mathrm{s}$. As the gas moves forward for LPG the gas velocity reduces to $6.5 \mathrm{~m} / \mathrm{s}$ to $13 \mathrm{~m} / \mathrm{s}$, for gasoline $5-10 \mathrm{~m} / \mathrm{s}$ and for alcohol 6.35 to $12.7 \mathrm{~m} / \mathrm{s}$ up to the pipe bend. It is observed that in all the three cases velocity inlet 1 pipe have almost same velocity till the contact region of the main pipe. But in the other three inlet pipes there is a slight backflow. It is observed in all the three cases that velocity goes on increasing till the pressure outlet. LPG has the maximum velocity range and the theoretical value of outlet velocity lies closer to gasoline as compared to LPG and alcohol. 


\section{Pressure Contours (fig. 9-11):}

From the pressure contours it can be observed that in all the three cases the pressure from inlet pipe one to the exit goes on decreasing, which is also a required condition for the flow to happen in the outlet direction. In case of gasoline, the first two inlet pipes have almost same pressure and then the pressure decreases. A slight back pressure can be seen at the joint of third inlet pipe.

In case of alcohol the pressure goes on reducing from the pipe bend of the first inlet pipe. A large region of back pressure can be observed. In case of alcohol, back pressure is observed higher than the other two cases. In case of LPG, the region of back pressure is near the end of inlet pipe 2 and inlet pipe 3. It is observed that alcohol gives the maximum exit pressure of range $602 \mathrm{~Pa}$ at the outlet. Whereas LPG gives $258 \mathrm{~Pa}$ and gasoline with the least pressure outlet gives $110 \mathrm{~Pa}$.

\section{Temperature Contours (fig. 12-17):}

It can be observed from the temperature contours that at the four inlets the temperature is same, since it is the outlet temperature of gas from engine cylinder (T4 in Otto cycle) and is assumed to be same for all the four inlets. The temperature variation from inlets to the outlet of the exhaust manifold in all the three cases are almost similar to each other throughout the path except near the pressure outlet. In the region near the pressure outlet the fluctuation of temperature of the exhaust gas is more in compared to other domains.

It can be observed that among the three simulations Alcohol gives the maximum outlet temperature in the range of 469 to $496 \mathrm{~K}$, followed by LPG in the range of $469-483 \mathrm{~K}$ and at last gasoline gives the temperature range of $456-483 \mathrm{~K}$ at exhaust manifold outlet.

From inlets as the gas moves forward initially the temperature reduces but at the pipe bend the temperature again increases. The gases from all the inlets mix together and final temperature range is achieved at pressure outlet. In case of gasoline the reduction in temperature from inlet to pipe bend is from $523 \mathrm{~K}$ to 361 $\mathrm{K}$ and at the pipe bend the temperature again increases to $416 \mathrm{~K}$. In LPG the reduction is from $523 \mathrm{~K}$ to $397 \mathrm{~K}$ and the increase in temperature at the pipe bend is up to $433 \mathrm{~K}$. In case of alcohol the temperature variation is from $523 \mathrm{~K}$ to $375 \mathrm{~K}$ and again up to $429 \mathrm{~K}$ at the pipe bend.

Figures 18-20 shows the variation of pressure, temperature and velocity of exhaust gas flow from inlet to outlet manifold. It matches with the fluid flow phenomena.
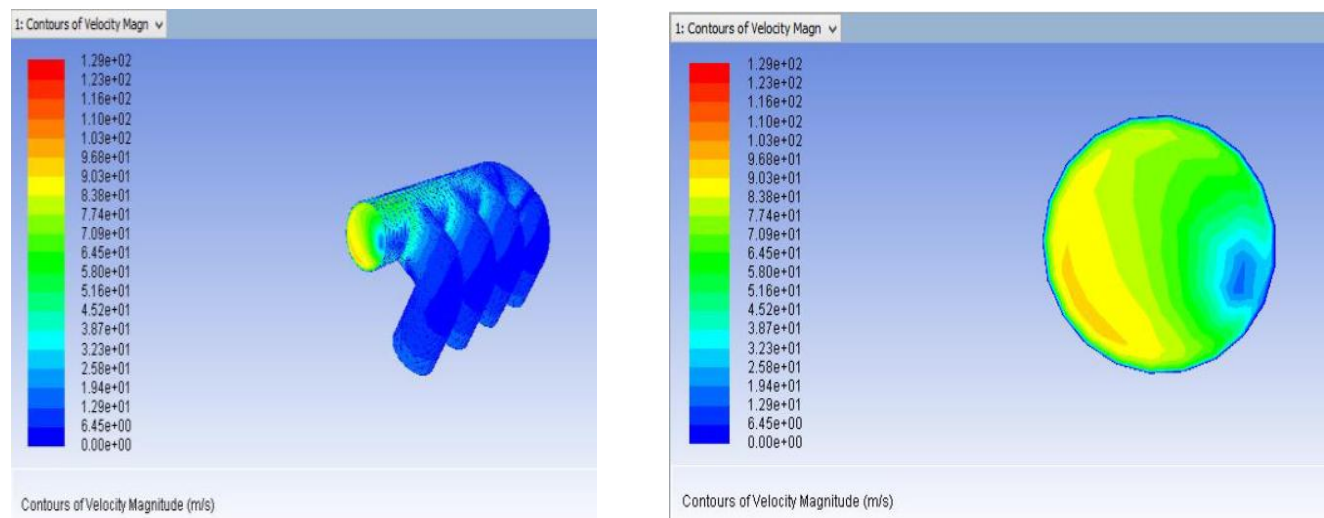

Fig.3: Velocity contour of exhaust manifold with $L P G$

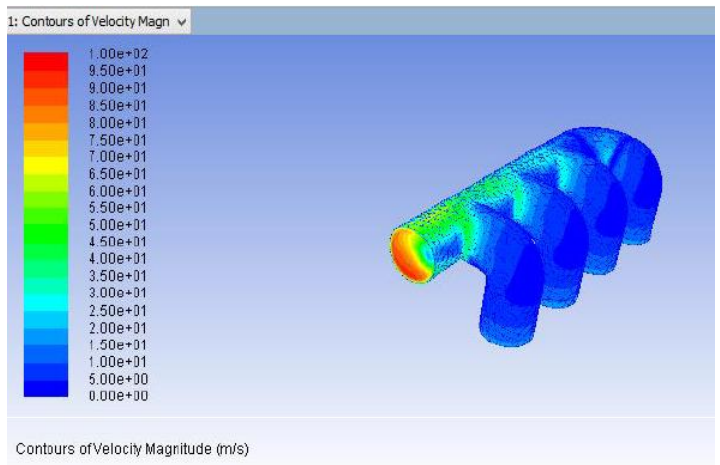

Fig. 4: Velocity contour of pressure outlet of exhaust manifold with $L P G$

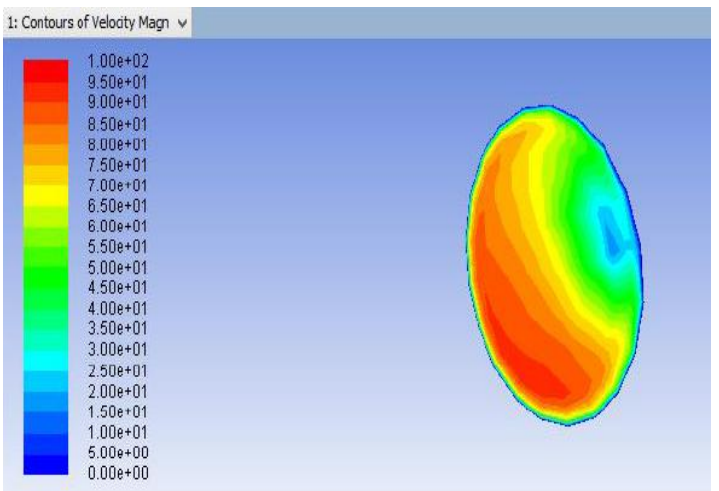

Fig. 5: Velocity contour of exhaust manifold with gasoline

Fig. 6: Velocity contour of pressure outlet of exhaust manifold with gasoline 


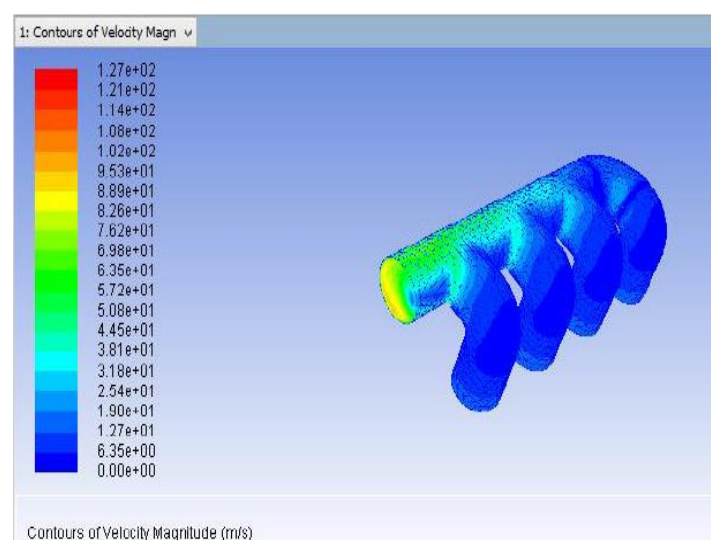

Fig. 7: Velocity contour of exhaust manifold with alcohol

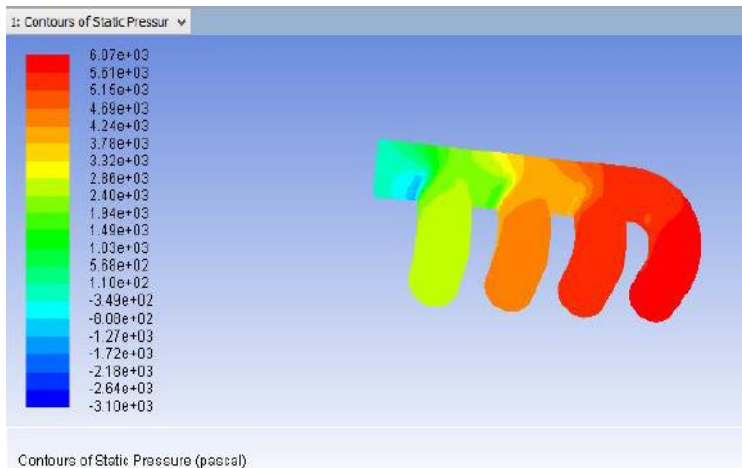

Contours of Static Prassure (pasco

Figure 9: Pressure contour of exhaust manifold with gasoline

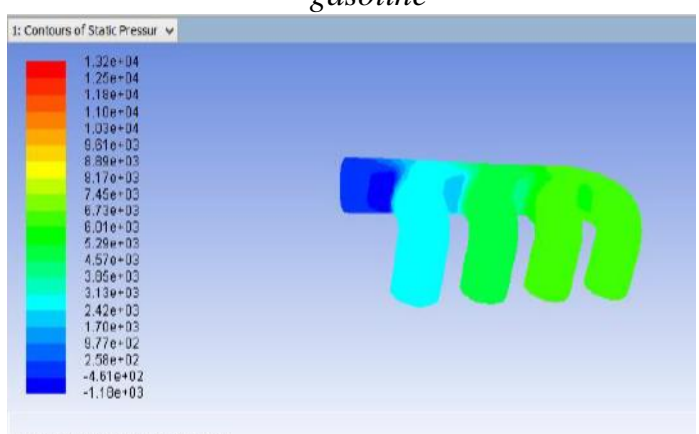

Contours or Statc Pressure (pasca)

Fig. 11: Pressure contour of exhaust manifold with $L P G$

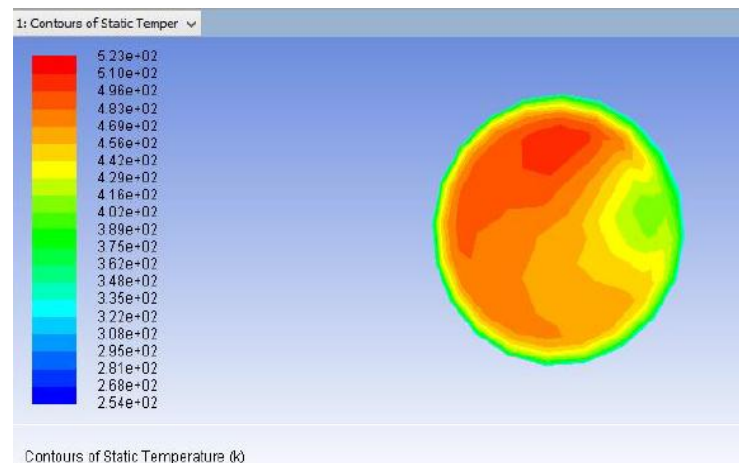

Fig. 13: Temperature contour of pressure outlet of exhaust manifold with gasoline

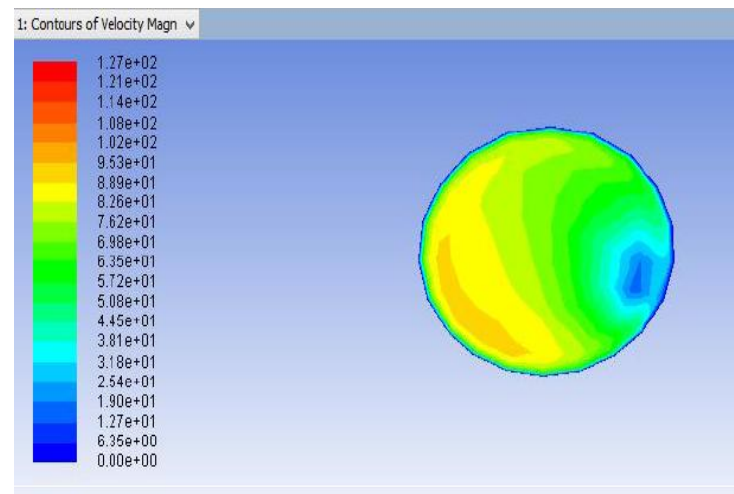

Contours of Velocity Nagnitude (m/s)

Fig. 8: Velocity contour of pressure outlet of exhaust manifold with alcohol

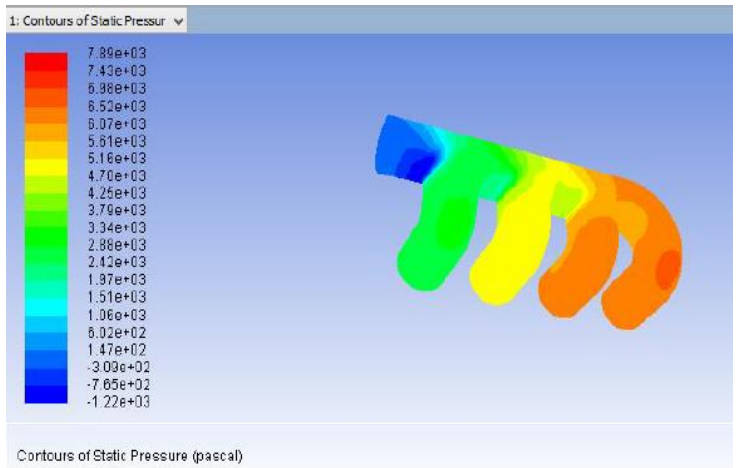

Figure 10: Pressure contour of exhaust manifold with alcohol

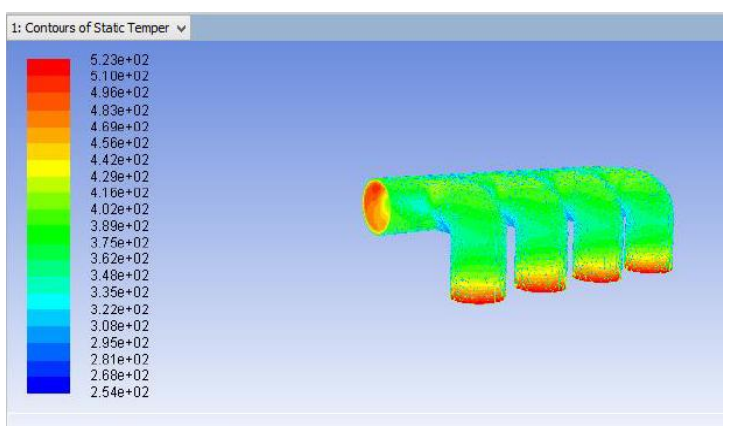

Contours of Static Temperature (k)

Fig. 12: Temperature contour of exhaust manifold with gasoline

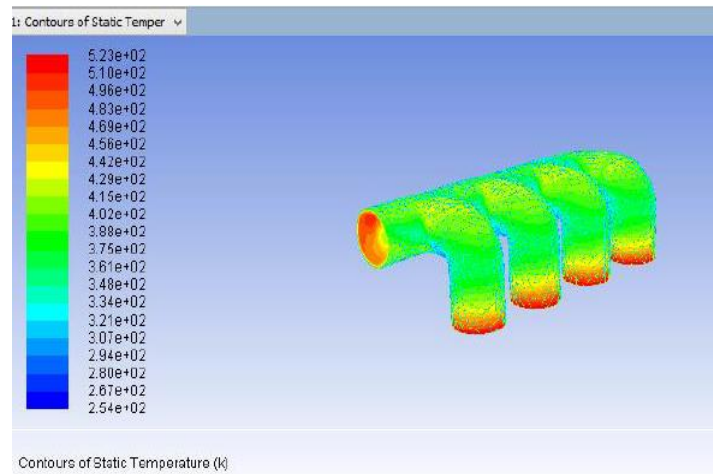

Fig. 14: Temperature contour of exhaust manifold with alcohol 


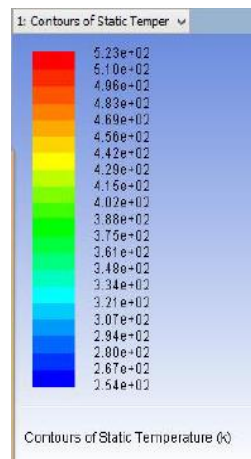

Fig. 15: Temperature contour of pressure outlet of exhaust manifold with alcohol

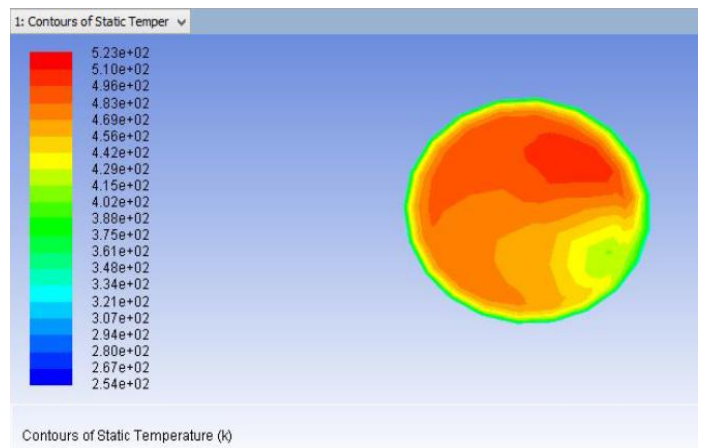

Fig. 17: Temperature contour of pressure outlet of exhaust manifold with $L P G$

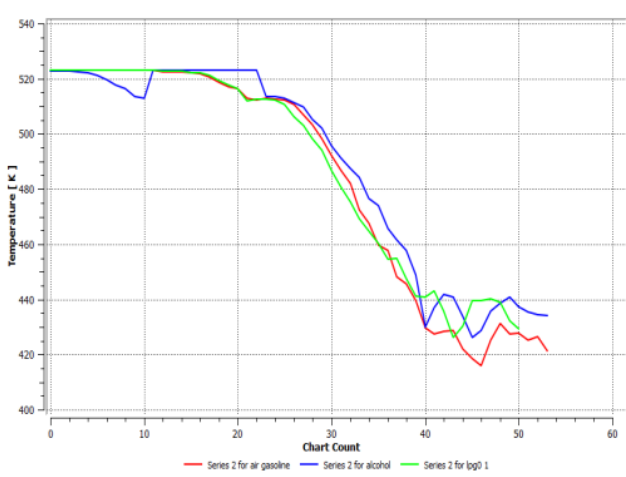

Fig. 19: Temperature graph for gasoline, alcohol and $L P G$

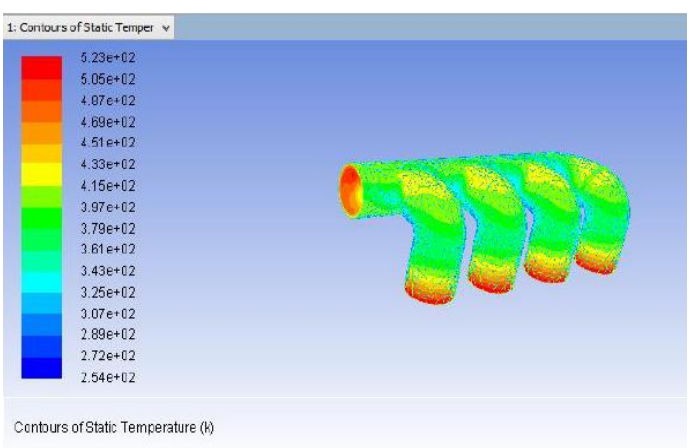

Fig. 16: Temperature contour of exhaust manifold with $L P G$

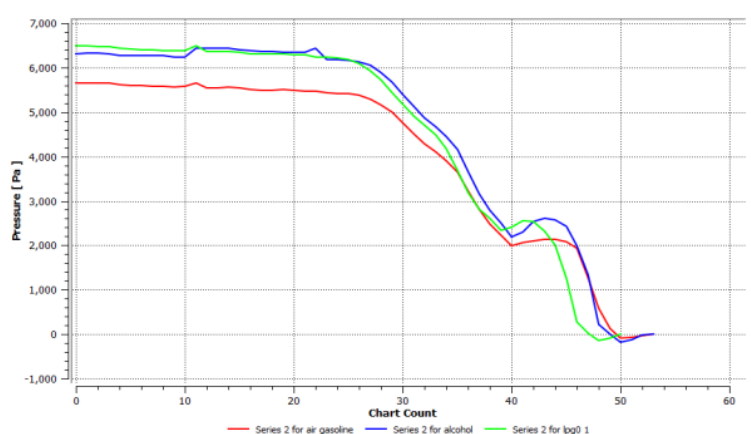

Fig. 18: Pressure graph for gasoline, alcohol and $L P G$

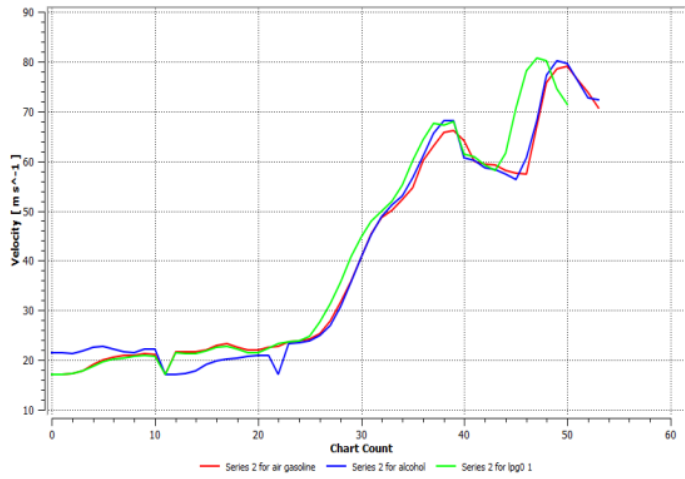

Fig. 20: Velocity graph for gasoline, alcohol and $L P G$

\section{Conclusion}

The back pressure in an exhaust manifold is an important criterion for efficiency of an IC engine. The lesser is the back pressure, the more work will be free by piston to reach the flywheel. From the above displayed results, it can be concluded that the flue gases produced by combustion of LPG had the lowest value of pressure difference at the back pressure zones than those of flue gases produced by gasoline and alcohol in the exhaust manifold. In all the three cases, a negative pressure zone is commonly generated at the intersection of main duct and the ducts from individual inlets that causes back pressure. Alcohol has the highest value of back pressure and has the most frequency of negative pressure difference. Gasoline has the least working pressure of the three and exhibits moderate zones of negative pressure difference while LPG has maximum working pressure followed by alcohol. The velocities of the flue gases from all the three fuels remain almost identical at their respective positions in the duct. The sudden valleys present in the curves are caused due to back pressure at those points. The maximum velocity of flue gases is achieved near the outlet of exhaust manifold as the pressure at that position is low so the gases rush out of the exit of the duct. The temperature of flue gases in all the cases cools down as the gases proceed towards the outlet of the exhaust manifold. The parts where the temperature rises are the points of mixing of gases, where the temperature rises due to collision and rubbing among the gas molecules. 
There is also some observable turbulence at the intersections of main duct and individual ducts from cylinders and also near the end of the manifold due to mixing of gases and high velocity.

\section{References}

[1]. Umesh K. S, Pravin V. K, and Rajagopal K. "CFD Analysis and Experimental Verification of Effect of Manifold Geometry on Volumetric Efficiency and Backpressure for Multi-cylinder SI Engine" International Journal of Engineering and Science Research, 3, 7, 342-353. 2013

[2]. Umesh K. S, Pravin V. K, and Rajagopal K. "Experimental Analysis of Optimal Geometry for Exhaust Manifold of Multi-cylinder SI Engine for Optimum Performance” International Journal of Automobile Engineering Research and Development, 3, 4, 11-12. 2013.

[3]. Umesh K. S, Pravin V. K, and Rajagopal K. "Experimental Investigation of Various Exhaust Manifold Designs and Comparison of Engine Performance Parameters for These to Determine Optimal Exhaust Manifold Design for Various Applications" ACEEE Conference Proceedings Series, 2, 711-730. 2013.

[4]. Jain Sweta, Agrawal AlkaBani, "Coupled Thermal - Structural Finite Element Analysis for Exhaust Manifold of an Off-road Vehicle Diesel Engine” International Journal of Soft Computing and Engineering (IJSCE) ISSN: 2231-2307, Volume-3, Issue-4, September 2013.

[5]. Kutaiba J.M. AL-Khishali, Mahmoud A. Mashkour \& Ehsan Shamil Omaraa, "Analysis of Flow Characteristics in Inlet and Exhaust Manifolds of Experimental Gasoline Combustion in A VCR Engine" Eng. \& Tech. Journal, Vol. 28, No. 7, 2010.

[6]. Rathnaraj, J.David "Thermomechanical Fatigue Analysis Of Stainless Steel Exhaust Manifolds" IRACST - Engineering Science and Technology: An International Journal (ESTIJ), ISSN: 2250-3498, Vol.2, No. 2, April 20

[7]. Satish Swathi, Prithiviraj Mani and Hari Sridhar, "Comparison of predictions obtained on an exhaust manifold analysis using conformal and indirect mapped interface" International Congress on Computational Mechanics and Simulation (ICCMS), IIT Hyderabad, 10-12 December 2012.

[8]. Mesut DURAT, Zekeriya PARLAK, Murat KAPSIZ, Adnan PARLAK, ve Ferit FIÇICI (2013) "CFD and Experimental Analysis on Thermal Performance of Exhaust System of A Spark Ignition Engine” Isı Bilimi ve Tekniği Dergisi, 33, 2, 89-99, 2013, J. of Thermal Science and Technology, C2013 TIBTD Printed in Turkey, ISSN 1300-3615

[9]. L'UBOMÍR MIKLÁNEK (2006) "Distortion of Measured Pressure in Exhaust-manifold due to Transducer Position" Josef Božek Research Centre, Czech Technical University in Prague, Czech Republic.

[10]. Saïd Zidat and Michael Parmentier, "Exhaust Manifold Design to Minimize Catalyst Light-off Time" 2003 SAE World Congress Detroit, Michigan March 3-6, 2003.

[11]. Kandylas, I.P., Stamatelos, A.M. "Engine exhaust system design based on heat transfer computation" Energy Conversion \& Management 40 (1999) 1057-1072.

[12]. Londhe A. and Yadav V. "Thermo-Structural Strength Analysis for Failure Prediction and Concern Resolution of an Exhaust Manifold" CAE, R\&D, Mahindra and Mahindra Ltd, Automotive Sector, Nasik, India, 2006, URL: https://static.aminer.org/pdf/PDF/000/565/390/a_methodology_for_analysis_of_failure_prediction_data.pdf, accessed on 12 December 2014

[13]. Taner Gocmez and Udo Deuster, "Designing Exhaust Manifolds Using Integral Engineering Solutions", 2007, URL: http://www.fev.com/fileadmin/user_upload/Media/TechnicalPublications/Design/ExhaustManifoldDesign.pdf, accessed on 12 December 2014

[14]. Zou, Bin, Hu, Yaqian, Liu, Zhien, Yan, Fuwu and Wang, Chao, "The Impact of Temperature Effect on Exhaust Manifold Thermal Modal Analysis" Research Journal of Applied Sciences, Engineering and Technology 6(15): 2824-2829, 2013 ISSN: 2040-7459; eISSN: 2040-7467 @ Maxwell Scientific Organization, 2013.

[15]. Bisane, Rajesh, Katpatal, Dhananjay, "Experimental Investigation \& CFD Analysis of An Single Cylinder Four Stroke C.I. Engine Exhaust System” IJRET: International Journal of Research in Engineering and Technology eISSN: 2319-1163, pISSN: 2321-7308, Volume: 03, Issue: 06, Jun-2014.

[16]. Yasar Deger, Burkhard Simperl, Luis P. Jimenez, "Coupled CFD-FE-Analysis for the Exhaust Manifold of a Diesel Engine" 2004, ABAQUS Users' Conference. 